\title{
The design of smart educational environments
}

\author{
Begoña Gros
}

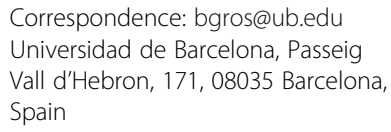

Correspondence: bgros@ub.edu Universidad de Barcelona, Passeig Vall d'Hebron, 171, 08035 Barcelona, Spain

\begin{abstract}
This paper discusses the key characteristics of smart learning and the main challenges to be overcome when designing smart educational environments to support personalisation. In order to integrate smart learning environments into the learning ecosystem and educational contexts, innovative uses and new pedagogical approaches need to be implemented to orchestrate formal and informal learning. This contribution describes the main characteristics of smart learning and smart learning environments and sustains the relevance of taking the participation of future users into account during the design process to increase knowledge of the design and the implementation of new pedagogical approaches in smart learning environments.

Keywords: Smart education, Seamless learning, Smart education, Smart learning environments, Participatory design
\end{abstract}

\section{Introduction}

In the literature of 1990 s it was quite common to describe the advantage of using information and communication technologies (ICT) in learning as the ability to learn anyplace, anytime, anywhere (Collis, 1996). Certainly, ICT has modified the conception of time and space, providing new opportunities to access information and modify knowledge production. The use of mobile devices has generated the idea that the place and context in which learning takes place is not very important. However, locations (physical and virtual) are not irrelevant; on the contrary, they are becoming increasingly important and the design of learning environments needs to orchestrate the different locations in which a person can learn, combining formal and informal situations. It is also relevant that mobile devices integrate location as an important aspect of adaptation and personalisation. The use of mobile devices offers users the chance to generate and control more aspects of real-world location-based environments or contexts (Cook et al. 2011).

In a traditional classroom the teacher is the main source of information and students are required to stay in the same place and participate simultaneously in the same activity, whereas in a situation of ubiquitous learning activities can be conducted in a different space and time for each student. In addition, teaching materials are available at all times and are accessible from any device. Sharples et al. (2014) used the concept of seamless learning to describe when a person experiences a

(c) 2016 The Author(s). Open Access This article is distributed under the terms of the Creative Commons Attribution 4.0 International License (http://creativecommons.org/licenses/by/4.0/), which permits unrestricted use, distribution, and reproduction in any medium, provided you give appropriate credit to the original author(s) and the source, provide a link to the Creative Commons license, and indicate if changes were made. 
continuity of learning across a combination of locations, times, technologies and social settings. "Seamless learning can be a collective or an individual process. It can extend across time and locations, offer ubiquitous access to learning resources, encompass physical and digital worlds, engage multiple types of device, and integrate different approaches to teaching and learning" Sharples et al. (2014, p. 24). Burbules (2012) notes that for learning to be effectively ubiquitous it requires a more distributed experience in time and space. It is well understood that a ubiquitous learning environment is one in which the student may be learning without even being fully aware of the situation. Along these lines, the limits between "work/play, learning/ entertainment, accessing/creating information, public/private, formal/informal are distinctions that have conceptually been clear but currently are becoming unclear" (Burbules 2012, p. 2).

Digital technology has promoted a new vision for learning. Chatti et al. (2010) summarised the future challenges in education very well when they said that learning is fundamentally personal, social, distributed, ubiquitous, flexible, dynamic and complex in nature. "A fundamental shift is needed towards a more personalised, social, open, dynamic, emergent and knowledge-pull model for learning, as opposed to the one-size-fits-all, centralised, static, top-down and knowledge-push models of traditional learning solutions." Chatti et al. (2010, p.67). While these are desirable educational outcomes, the realisation requires new learning designs based on new pedagogical approaches and a more effective use of technology capable of supporting and guiding individual learners. The concept of smart learning emphasises the importance of technological design to make learning better. In a way, it is a concept that is related to the term 'technology-enhanced learning' (TEL), which has been used especially in Europe.

Unlike other terms, TEL implies a value judgement: 'enhanced' suggests that something is improved or superior in some way, but what exactly will be enhanced when technology is used for teaching and learning, how will enhancement be achieved, and how can an enhancement be determined? Is the enhancement concerned with increasing technology use or improving the environment in which educational activities are undertaken? Similar questions arise when talking about smart learning. However, the term 'smart learning' does not only refer to the idea of improving learning, it also emphasises the need for adaptation and personalisation, taking into account the places where learning occurs. In smart learning the location in real time is important data required by systems in order to adapt the content and situation to the learner.

The aim of this contribution is to analyse the main challenges to be overcome when designing smart educational learning environments. The authors maintain that one of the most important features of smart learning is that the data used serves as feedback for the learner to support personalised learning. Based on personal experience, the present authors believe that applying participatory design methodologies helps to develop smart learning environments tailored to the needs and socio-cultural context of the learners.

The following sections review the main characteristics of smart learning, smart learning environments and smart education, and the principal challenges facing the design of smart learning environments are analysed. 


\section{Smart learning}

According to Zhu et al. (2016, p. 3), "there is not a clear and unified definition of smart learning so far. Multidisciplinary researchers and educational professionals are continuously discussing the concept". In fact, many different definitions can be found in almost all the articles that emphasise multiple aspects and characteristics of smart learning published since 2014 in the journal Smart Learning Environments. However, there are some common and crucial elements identified by most researchers in this field. The first highlights that smart learning is founded on two different types of technology: smart devices and intelligent technologies.

Smart devices refer to artefacts that exhibit some properties of ubiquitous computing, including (although not necessarily) artificial intelligence; for instance, the Internet of things, wearable technology in the form of an accessory such as glasses, a backpack, or even clothing.

The use of intelligent technologies, such as cloud computing, learning analytics or big data, focuses on how learning data can be captured, analysed and directed towards improving learning and teaching, and supporting the development of personalised and adaptive learning (Mayer et al. 2013; Picciano 2012).

Despite this distinction between smart devices and intelligent technologies, the two are in fact related, because neither type of technology is independent. For instance, the Internet of things and most wearable technology require big data to generate personal information and provide the user with feedback.

Besides the technical characteristics, it is useful to analyse the characteristics that outline smart learning. Along these lines, Zhu, et al. (2016, p. 11) describe ten key features that define smart learning:

1. Location-aware: in smart learning the location in real time is important data that the systems need in order to adapt the content and situation to the learner;

2. Context-aware: exploring different activity scenarios and information;

3. Socially-aware: sensing social relationships;

4. Interoperable: setting standards for different resources, services and platforms;

5. Seamless connection: providing continuous service when any device connects;

6. Adaptable: pushing learning resources according to access, preference and demand;

7. Ubiquitous: predicting learner demands until clearly expressed, providing visual and transparent access to learning resources and services;

8. Whole record: recording learning path data to mine and analyse in depth, then providing reasonable assessment, suggestions and pushing on-demand service;

9. Natural interaction: transferring the senses of multimodal interaction, including position and facial expression recognition;

10. High engagement: immersion in multidirectional interactive learning experiences in technology-enriched environments.

In summary, in smart learning, location in real time can be important to adapt the content and situation to the learner. However, location is not always a necessary condition in smart learning. The most important characteristic is that the system will be able to advise and predict learner needs. Smart learning is a learning system that provides advising learners to learn in the real world. 


\section{Characteristics of smart learning environments}

The implementation of smart learning environments goes beyond the application of smart technology. A smart learning environment not only enables learners to access digital resources and interact with learning systems in any place and at any time, it also actively provides the necessary learning guidance, hints, supportive tools or learning suggestions in the right place, at the right time and in the right form.

Spector (2014, p. 2) considers that a smart learning environment is one that is "effective, efficient and engaging". Moreover, the present authors consider that it is important to support the fusion of technology and pedagogy to create a coherent ecosystem that provides "real-time and ongoing evidence of changes in knowledge, instilling skills which are seamlessly transferred to learners as they move from one learning context to another" (Chen et al. 2016, p. 1).

According to Hwang (2015) three key features define a smart learning environment:

1. Context-aware: the system must be able to provide learning support based on learners' online and real-world status;

2. Adaptive support: the system must offer instant and adaptive support to learners based on their individual needs from different perspectives (learning performance, learning behaviours, profiles, personal factors, etc.), as well as the online and realworld contexts in which they are situated;

3. Adaptive interface: the system must be able to adapt the interface to the user (ways of presenting information, learning preferences, learning performance, etc.) The user interface can be any mobile device (smartphones, tablet computers, etc.), wearable device (a digital wristwatch), or even ubiquitous computing systems embedded in everyday objects.

Hwang (2014) specified the potential criteria for a smart learning environment as being context-aware, able to offer learners instant and adaptive support and adapt the learner interface and subject contents. A smart learning environment aims to support learners to obtain new knowledge, even while they are engaged in leisure activities. It plays the role of a coach, or guide, who seeks opportunities to advise learners on their daily life by taking their needs and preferences into account. To sum up, the goal of a smart learning environment is to provide self-learning, self-motivated and personalised services.

According to Spector (2014), it is also highly desirable for the design of smart learning environments to provide motivation for a variety of learners, recognising learners' competencies, learning styles and interests. Moreover, the learning environment must provide personalised assignments and/or formative feedback, and should include pedagogical strategies that support:

a. Conversation: the learning environment can engage the learner in a dialogue or facilitate a group dialogue on a relevant topic or problem;

b. Reflection: the learning environment can generate self-assessment based on student progress and performance, preferably suggesting activities and attributes in the learning environment that can be adjusted to improve overall effectiveness; 
c. Innovation: the learning environment uses new and emerging technologies and leverages innovative technologies in creative ways to support learning and instruction;

d. Self-organisation: the learning environment can rearrange resources and control mechanisms to improve its performance over time based on data that are automatically collected and used to refine how the environment interacts with learners in various circumstances.

\section{Smart learning environments and learning ecology}

The present authors consider that smart learning environments are an important component of the learning ecology. The concept of learning ecology provides a systemic overview that goes beyond a simplistic techno-centric point of view. It is important to understand that technologies are embedded within learners' habitual life experiences. John Seeley Brown introduced this idea in his influential article from 2000 entitled "Growing Up Digital: How the Web Changes Work, Education, and the Ways People Learn". Seeley used it to show how new technologies encourage new niches and habitats, requiring new collective and individual behaviours. Along these lines, Barron's learning ecologies framework (2006) explains how learning takes place across settings and identifies the possible synergies and barriers between them, including the role of technology, in making boundaries more permeable and allowing for new levels of agency in learning. She developed a learning ecology framework based on three assumptions (Barron, 2006, pp. 200-201): 1) a variety of ideational resources can spark and sustain interest in learning; 2) people not only choose, but also develop and create learning opportunities for themselves once they are interested, assuming they have the time, freedom and resources to learn; and 3) interest-driven learning activities are boundary-crossing and self-sustaining. This individual view of learning ecologies views the learner as the main actor in the network, responsible for maintaining social relationships and creating meanings throughout physical and virtual contexts (Haythornthwaite \& De Laat 2012).

In summary, according to Hwang (2015), a smart learning environment must:

- Detect and take into account the real-world contexts.

- Situate learners in real-world scenarios.

- Adapt learning interfaces for individual learners.

- Adapt learning tasks for individual learners.

- Provide personalised feedback or guidance.

- Provide learning guidance or support across disciplines.

- Provide learning guidance or support across contexts.

- Recommend learning tools or strategies.

- Consider learners' online learning status.

- Consider learners' real-world learning status.

- Facilitate both formal and informal learning.

- Take multiple personal and environmental factors into account.

- Interact with users via multiple channels.

- Provide learners with support in advance, across real and virtual contexts. 
The use of technologies embedded within learners' habitual life experiences has important consequences for the pedagogical methods of formal education. The inclusion of smart learning environments in educational contexts increases complexity and education professionals need to introduce innovative uses and new pedagogical approaches. The next section discusses the main pedagogical challenges when designing learning ecosystems that integrate smart learning.

\section{Smart learning and smart pedagogies}

In the early 1990s, the use of technology to support classroom instruction was scarce due to the lack of teacher knowledge. For this reason, the earliest professional development programmes focused on hardware and software use. However, it soon became clear that this was not a good strategy, because the use of ICT had to be embedded in educational methodology. Many efforts have been made to effectively integrate technology as an educational tool as a means to promote student-centred learning. Currently, the next challenge ahead is to design learning ecosystems that integrate smart learning to personalise and self-regulate learning. According to Zhu, et al. (2016, p. 15), "the objective of smart education is to improve learners' quality of lifelong learning. It focuses on contextual, personalised and seamless learning to promote learners' emerging intelligence and facilitate their problem-solving ability in smart environments". Similarly, Kim et al. (2014) consider that smart education is a learner-centric and serviceoriented educational paradigm. Middleton (2015) also believes that smart education must be developed based on learner-centric aspects. MEST (2011) present the features of smart learning defined as self-directed, motivated, adaptive, resource-enriched and technology-embedded, while Lee (2015) proposed that the features of smart learning include formal and informal learning, social and collaborative learning, personalised and situated learning, and application and content focus.

What seems clear is that this type of education will raise new pedagogical issues. Researchers and educators need to develop new thoughts about pedagogy based on existing theories, such as constructivism, cognitive load theory and new ones such as connectivism and networked learning (Gros, 2016). New learning concepts might provide good opportunities for researchers to develop new strategies for helping learners more effectively and efficiently gain knowledge and solve problems in the real world.

Smart pedagogies must take into account the knowledge creation metaphor of learning that highlights competencies in producing knowledge. "The knowledge-pull approach to learning is based on providing learners with access to a plethora of tacit/ explicit knowledge nodes and handing over control to them to select and aggregate the nodes in the way they deem fit, to enrich their personal knowledge networks" (Chatti, et al. 2010, p. 82). These skills are increasingly related to the use of digital technology which provides a flexible way to support modelling, sketching, testing and social interactions.

The ubiquity of technology calls for a shift away from low-level use of technology, such as drilling, practice and looking up information. Rather, smart education encourages a 'high-level' use of technology, utilising it as a 'mind tool' or 'intellectual partner' for creativity, collaboration and multimedia productivity. Technology must enable and accelerate learning relationships between teachers and students and between students 
and other learning partners, such as peers, mentors and others with similar learning interests. Deep learning tasks re-structure learning activities from a singular focus on content mastery to the explicit development of students' capacities to learn, create and proactively implement their learning. In their most effective instances, deep learning tasks are guided by clear and appropriately challenging learning goals, which ideally incorporate both curricular content and students' interests or aspirations; include specific and precise success criteria that help both teacher and student know how well the goals are being achieved; and, incorporate feedback and formative evaluation cycles into the learning and doing processes, building students' self-confidence and proactive dispositions.

Despite the advances in psychological research as well as in educational technology, assessment practice in educational institutions has not changed for decades. There is a need to move beyond traditional forms of assessment, using new methods to combine different levels. The development of smart learning technologies provides great potential for the enhancement of automated assessments. According to Kopainsky et al. (2012) learning analytics systems can be used to balance evidence-based, real-time assessment (especially self-assessment) with intelligent digital systems designed to foster critical thinking and problem solving. Data from tracking and managing learning activities can inform learning design by providing evidence to support the choice of media and sequence of activities. Such analytical feedback for students can be continuous during a course and enable learners to focus on areas of weakness.

Besides the use of technology, new pedagogies emphasise the active engagement of students in their own learning, learner responsibility, metacognitive skills and a dialogical, collaborative model of teaching and learning. For this reason, self-assessment and peer-assessment are also very important. Andrade and Du (2007, p. 160) provide a helpful definition of self-assessment that focuses on the formative learning that it can promote: "Self-assessment is a process of formative assessment during which students reflect on and evaluate the quality of their work and their learning, judge the degree to which they reflect explicitly stated goals or criteria, identify strengths and weaknesses in their work, and revise accordingly".

Peer assessment involves students taking responsibility for assessing the work of their peers. They can therefore be engaged in providing feedback for their peers. It is a powerful way for students to gain a better understanding of assessment criteria and can also transfer some ownership of the assessment process to them, thereby potentially increasing their motivation and engagement.

\section{The design of smart learning environments: participation and feedback}

In the authors' view, smart learning environments involve taking into account the context, cultural resources and socio-cultural features of formal and informal learning environments. Smart learning environments are not only linked with the idea of improving learning, they also emphasise the need for adaptation and personalisation depending on where learning occurs. Thus, smart learning poses important challenges for evaluation as the content may not be fixed and the activity may extend cross formal and informal settings. The present authors consider that there are two key issues that must be taken into account when designing smart learning environments: i) user 
participation in the design, and, ii) the provision of useful support to offer users appropriate feedback.

i) Participatory design

Traditional design methodology restricts learner participation to a consultative role, where design decisions are taken by designers and/or developers. Traditional development adopts a systematic approach to analysis, design and testing, without necessarily using a specific user model. However, users are an important resource and can be partners in the design process to ensure that technology is useful and usable. The authors consider that the potential for smart learning depends on the design of the learning environment and it is important to design the ecosystems of learning using participatory processes. In contrast to the image of the quantified student as a data object acted upon by algorithmic techniques, smart learning must emphasise the idea of 'smart learners'.

The field of learning design has developed in recent years and now offers a set of methods, tools, systems and models (Goodyear \& Retalis, 2010; Mor \& Craft 2012) that can empower educators in the design of scenarios that provide richer learning experiences. The design should articulate and orchestrate the disciplinary content, pedagogical theory, experience based on practice and the use of increasingly diverse and sophisticated technological resources (Goodyear \& Retalis, 2010). Design is, by nature, iterative and collaborative. It requires discussion, reflection, critique and implementation. Designing for complex assemblages of humans and things requires an epistemic fluency that is rare, indeed sometimes frowned upon, in educational practice (Goodyear \& Markauskaite, 2009).

In the design of smart learning environments, it is necessary to take into account that the user will interact with heterogeneous devices that must be successfully integrated and interconnected. According to Pons et al. (2015, p. 511), "it is unlikely that developers can come up with systems capable of discovering the user's contextual preferences with a high degree of accuracy in all cases without any input from users themselves. The user's preferences should therefore form the key knowledge to be identified during the initial stages of the configuration."

Participatory design is being used to increase the knowledge of smart device design. For instance, Pons et al. (2015) applied participatory methodologies to design a visual language and tool to be used when creating future tangible tabletop-based editors for personalising smart environments. The design has served to identify the characteristics of visualisation, taking into account differences in the learners' knowledge.

Durall and Leinonen (2015) applied participatory design to develop Feeler, a prototype created to help people develop an awareness of how different habits and mental states have an impact on their learning. Thus, Feeler aims to foster an awareness of and reflection on study activity. Feeler's design is based on the assumption that learning technology built on monitoring physiological data should aim to empower students by helping them understand the different aspects that have an impact on their learning performance. Therefore, Feeler explores several strategies for supporting reflection in the prototype design such as the creation of time, asking reflective questions and leaving some aspects incomplete in order to encourage users to enquire into the meaning. 
Although these cases are prototypes, some authors (Durall and Leinonen; 2015, Pons et al. 2015) consider the design adopted very relevant for opening a discussion on the role of data to support meaningful and personalised information.

ii) Visualisation of data

Feedback has been considered a key tool for helping students to improve performance. Traditional feedback usually relates to learners' mechanisms of communication with their teachers and colleagues. As mentioned in the previous section, the use of technology adds new possibilities for tracking learners' activity and offers them more immediate feedback about their learning performance. However, most efforts to use learning analytics focus on providing information for instructors in order to refine their pedagogical strategies (Knight et al., 2013). Very rarely are students considered the main receivers of learning analytics data or given the opportunity to use the information to reflect on their learning activity and self-regulate their learning more efficiently. Some authors warn that learning analytics could actually disempower learners by making them reliant on institutional feedback (Buckingham Shum et al. 2012). Most analytics studies have drawn on historical data to identify patterns in students' learning behaviour which are then related to academic performance and/or retention. However, much of this work lacks an understanding of the pedagogical context that influences student activities, and how identifying patterns in students' learning behaviours can be used to influence and contribute to more positive teaching and learning experiences. Essentially there is a knowledge gap for teachers attempting to bridge the divide between the information provided by learning analytics and the types of pedagogical actions designed by teachers to support learning. The field of learning design offers a way to address this gap by helping teachers to articulate the design and intent of learning activities which can be used as a guide for interpreting learning analytics data.

In response to the use of learning analytics as a tool at the service of the institution, a growing number of scholars have begun to advocate student-centred analytics (Kruse \& Pongsajapan 2012). In line with these authors, we consider that learning analytics can and should be used as a tool for reflection and metacognition to support selfregulated learning (Durall \& Gros, 2014). It is vital to identify the main challenges in the design of learning environments that make use of learning analytics to foster reflection. The most urgent challenges to be faced fall into two categories: data and visualisation. What sort of data is most meaningful for learners? What types of visualisation can foster reflection most successfully?

Transforming data into knowledge is a cognitive process that can be supported by the way in which data is made available. Information visualisation has been recognised as a tool for sense-making, since it helps synthesise complex information and facilitates comparisons and inferences (Durall \& Toikkanen, 2013). Therefore, in order to truly use analytics to help students become autonomous learners, it is necessary to adopt a student-centred approach.

There is a need to rethink how learning indicators are selected and to what extent they contribute to conceiving learning as a process instead of in terms of outcomes. In this regard, allowing students to decide what aspects they are going to monitor and 
analyse could help make learning analytics a tool for reflection on smart learning environments.

\section{Conclusion}

Learning anytime, anywhere is not a novel concept. However, where such processes are considered a common activity during life, it is important to explicitly design and intentionally support them. As mentioned above, smart learning environments must integrate formal and informal learning in order to create autonomous adaptive learning environments to support individual learners. These environments need to use big data and learning analytics techniques to integrate real-time information about learners' location and historical data to identify meaningful learning patterns. It is very important to take into account that smart learning environments involve context-awareness that can combine a physical classroom with many virtual learning environments.

According to Boulanger et al. (2015), a new concept of 'Education as a Service' is emerging as an approach to deal with the challenges of global and open markets. Educational resources in this approach are made easily accessible to global learners by delivering them as a service. From this perspective, one can expect traditional education organisational structures and teaching processes to undergo great changes. For example, lectures may be separated from the course itself. Some of the lectures may be given by a teacher other than the teacher responsible for the course. Assessments may be separated too, where a third party may conduct the tests instead of the course teacher.

Services must consider the learners' viewpoint and learning experience. In a smart learning environment, learners would have different service choices at different learning stages, where these services are provided by different educational facilities, either online or physically. Due to the rather blurred lines between formal and informal learning, and the increasing focus on informal learning, it may not be necessary to distinguish these two learning formats separately in the future.

Knowing more about students' learning performance and perceptions is vital for researchers to be able to develop more effective smart learning environments. An evaluation can be conducted using various aspects, such as learning achievement, problem-solving ability, self-efficacy and self-regulation. In the meantime, it is worth investigating the effects of smart learning environments on the learning performance and perceptions of students with different learning styles, cognitive styles, or other personal characteristics.

Having an in-depth understanding of learners' behaviours and learning patterns will be very important to researchers and educators in developing more effective learning tools and strategies.

Author's information

Begoña Gros is full professor of Education at the University of Barcelona. Her research is centred on the use of ICT to support learning, learning design, game-based learning as well as innovation. She has co-authored more than 70 peer-reviewed publications in scholarly journals and conference proceedings, and has co-authored or edited six books. 
Received: 14 June 2016 Accepted: 30 August 2016

Published online: 06 September 2016

\section{References}

H. Andrade, Y. Du, Student responses to criteria-referenced self-assessment. Assess. Eval. High. Educ. 32(2), 159-181 (2007)

B. Barron, Interest and self-sustained learning as catalysts of development: A learning ecology perspective. Hum. Dev. 49(4), 193-224 (2006)

D. Boulanger, J. Seanosky, V. Kumar, K. Panneerselvam, T.S. Somasundaram, Smart learning analytics, in Emerging issues in smart learning (Springer, Berlin Heidelberg, 2015), pp. 289-296

S. Buckingham Shum, D. Gašević, R. Ferguson (eds.), Proceedings of 2nd International Conference on Learning Analytics and Knowledge, LAK12 (ACM, New York, 2012)

N.C. Burbules, Ubiquitous learning and the future of teaching. Encounters. Educ. 13(3), 3-14 (2012)

M.A. Chatti, M.R. Agustiawan, M. Jarke, M. Specht, Toward a Personal Learning Environment Framework. Int. J. Virtual. Pers. Learn. Environ. 1(4), 66-85 (2010)

N.S. Chen, I.L. Cheng, S.W. Chew, Evolution Is not enough: Revolutionizing Current Learning Environments to Smart Learning Environments. Int. J. Artif. Intell. Educ. 26(2), 561-581 (2016)

B. Collis, Tele-learning in a digital world. The future of distance learning (International Thomson Computer Press, London, 1996)

J. Cook, N. Pachler, B. Bachmair, Ubiquitous mobility with mobile phones: A cultural ecology for mobile learning E-learning Digit. Media 8(3), 181-195 (2011)

E. Durall, B. Gros. Learning Analytics as a Metacognitive Tool. (CSEDU, Barcelona, 2014), pp. 380-384.

E. Durall, T. Leinonen, Feeler: supporting awareness and reflection about learning through EEG data, in Proceedings of the 5th Workshop on Awareness and Reflection in Technology Enhanced Learning In conjunction with the 10th European Conference on Technology Enhanced Learning, 2015, pp. 67-73

E. Durall, T. Toikkanen, Feeler: Feel Good and Learn Better: A Tool for Promoting Reflection about Learning and WellBeing. in Proceedings of the 3rd Workshop on Awareness and Reflection in Technology-Enhanced Learning, ed. by M. Krogstie, B. Moore, A. Pammer, V. Pannese, L. Prilla, M. Reinhardt, W. Ullmann, T.D. Kravcik. (CEUR Workshop Proceedings, 2013), pp. 83-89. http://ceur-ws.org/Nol-1103/paper6.pdf

P. Goodyear, L. Markauskaite, Teachers' design knowledge, epistemic fluency and reflections on students' experiences. 32nd Higher Education Research and Development Society of Australasia Annual Conference HERDSA 2009 (Higher Education Research and Development Society of Australasia, Milperra, 2009)

P. Goodyear, S. Retalis. Technology-enhanced learning (Sense Publishers, Boston, 2010)

B. Gros, The Dialogue Between Emerging Pedagogies and Emerging Technologies, in The Future of Ubiquitous Learning (Springer, Berlin Heidelberg, 2016), pp. 3-23

C. Haythornthwaite, M. De Laat, Social network informed design for learning with educational technology. Informed design of educational technologies in higher education: Enhanced learning and teaching, 2012, pp. 352-374

G.J. Hwang, Definition, framework and research issues of smart learning environments-a context-aware ubiquitous learning perspective. Smart Learn. Environ. 1(1), 1-14 (2014)

G.J. Hwang, H.C. Chu, C. Yin, H. Ogata, Transforming the educational settings: innovative designs and applications of learning technologies and learning environments. Interact. Learn. Environ. 23(2), 127-129 (2015)

S.H. Kim, N.H. Park, K.H. Joo, Effects of Flipped Classroom based on Smart Learning on Self-directed and Collaborative Learning. Int. J. Control Automation 12(7), 69-80 (2014)

S. Knight, S. Shum, K. Littleton, Collaborative sensemaking in learning analytics, in Viewing education as a site of work practice, co-located with the 16th ACM Conference on Computer Support Cooperative Work and Social Computing (CSCW, San Antonio, 2013)

B. Kopainsky, P. Pirnay-Dummer, S.M. Alessi, Automated assessment of learners' understanding in complex dynamic systems. Syst. Dyn. Rev. 28(2), 131-156 (2012)

A. Kruse, R. Pongsajapan Student-centered learning analytics. CNDLS Thought Papers, 1-9 (2012). Retrieved June 2, 2016. https://cndls.georgetown.edu/m/documents/thoughtpaper-krusepongsajapan.pdf

A. Lee, Authentication scheme for smart learning system in the cloud computing environment. J. Comput. Virol. Hacking Tech. 11(3), 149-155 (2015)

V. Mayer, K. Schönberger, K. Cukier, Big data: A revolution that will transform how we live, work, and think (Houghton Mifflin Harcourt, Boston, 2013)

MEST: Ministry of Education, Science and Technology of the Republic of Korea, Smart education promotion strategy, President's Council on National ICT Strategies, 2011

A. Middleton, Smart Learning: Teaching and Learning with Smartphones and Tablets in Post-Compulsory Education (MELSIG \& Sheffield Hallam University, Sheffield, 2015)

Y. Mor, B. Craft, Learning design: reflections upon the current landscape. Res. Lear. Technol. 20, 85-94 (2012)

A.G. Picciano, The evolution of big data and learning analytics in American Higher Education. J. Asynchronous Learn. Netw. 16(3), 9-20 (2012)

P. Pons, A. Catala, J. Jaen, Customizing smart environments: A tabletop approach. J. Ambient Intell. Smart Environ. 7(4), 511-533 (2015)

M. Sharples, A. Adams, R. Ferguson, M. Gaved, P. McAndrew, B. Rienties, M. Weller, D. Whitelock, Innovating Pedagogy. Open University Innovation Report 3 (The Open University, Milton Keynes, 2014)

J.M. Spector, Conceptualizing the emerging field of smart learning environments. Smart Learn. Environ. $1(1), 2-10(2014)$

Z.-T. Zhu, M.-H. Yu, P. Riezebos, A research framework of smart education. Smart Learn. Environ. 3(1), 1-17 (2016) 